\title{
Article
}

\section{Fungi as endophytes in Chinese Artemisia spp.: juxtaposed elements of phylogeny, diversity and bioactivity}

\section{Cosoveanu $\mathrm{A}^{\mathbf{1}^{*}}$, Hernandez $\mathrm{M}^{2}$, Iacomi-Vasilescu $\mathrm{B}^{3}$, Zhang $\mathrm{X}^{4}$, Shu $\mathrm{S}^{4}$, Wang $\mathbf{M}^{4}$ and Cabrera $\mathbf{R}^{1}$}

\author{
${ }^{1}$ Departmento de Botánica, Ecología y Fisiología vegetal, Facultad de Ciencias, Universidad de La Laguna, Tenerife, \\ Avda. Astrofisico Fco. Sanchez s/n, La Laguna, 38207, Islas Canarias, Spain \\ ${ }^{2}$ Departamento de Bioquímica, Microbiología, Biología celular y Genética, Instituto Universitario de Enfermedades \\ Tropicales y Salud Publica de Canaria, Tenerife, Avda. Astrofisico Fco. Sanchez s/n 38207, Islas Canarias, Spain \\ ${ }^{3}$ Departamentul de Stiintele Plantelor, Facultatea de Agricultura, Universitatea de Stiinte Agronomice si Medicina \\ Veterinara, Bd. Marasti 59, 11464, Bucuresti, Romania \\ 4 College of Plant Science\&Technology, Huazhong Agricultural University, 430070, Wuhan, China
}

Cosoveanu A, Cabrera R, Hernandez M, Iacomi-Vasilescu B, Zhang X, Shu S, Wang M 2016 Fungi as endophytes in Chinese Artemisia spp.: juxtaposed elements of phylogeny, diversity and bioactivity. Mycosphere 7(2), 102-117, Doi 10.5943/mycosphere/7/2/2

\begin{abstract}
Fungal endophytes were isolated from Artemisia lavandulifolia, A. tangutica, A. brachyloba, A. subulata, A. argy and A. scoparia in two Chinese localities, Qichun and Wuhan. 21 species were identified as belonging to one of the following: Diaporthe, Colletotrichum, Nigrospora, Botryosphaeria, Aspergillus, Penicillium, Neofusicoccum, Cercospora, Rhizoctonia, Alternaria and Curvularia. The evolutionary relationships were estimated through a phylogenetic tree using ITS1-5.8S-ITS2 region sequences. Members of the Diaporthaceae family were not clustered with Trichosphaeriaceae and Glomerellaceae though all are members of the Sordariomycetes class. Analysis of fungal diversity engaged various indices with results revealing contradictory aspects. Two new genera and two new species were reported as endophytes in Artemisia spp. (Nigrospora, Curvularia, Neofusicoccum parvum and Penicillium chrysogenum). Only two fungal species were found common in both localities. In dual culture assays with Sclerotinia sclerotiorum, Alternaria alternata and Fusarium oxysporum, Nigrospora endophytes provoked lysis, parasitism and had the highest values as antagonists against all pathogens. Fungal endophyte extracts were assayed against the mentioned pathogens. The three extracted fungi with the highest activity were: Botryosphaeria dothidea and Curvularia geniculata against A. alternata and Curvularia spicifera against $S$. sclerotiorum.
\end{abstract}

Key words - evolutionary relationships - fungal endophytes - medicinal plants - phytopathogens

\section{Introduction}

Endophytic fungi (EF) are estimated to be represented by at least one million species residing in plants (Idris et al. 2013). While some endophytic fungi appear to be ubiquitous (e.g. Fusarium spp., Alternaria spp., Pestalotiopsis spp., Aspergillus spp, Botryosphaeria spp.) others apparently present host specificity and/or host preference (Petrini 1996, Suryanarayanan et al. 2000, Schulz \& Boyle 2005, Hu et al. 2007, Slippers \& Wingfield 2007, Pang et al. 2008, Toju et al. 2013). 
Many endophytes of the same species are often isolated from the same plant and only one or a few strains produce highly biologically active compounds in culture (Li et al. 1996). During the long period of co-evolution, endophytic fungi have gradually adapted themselves to their special microenvironments by genetic variation; including suggestions as uptake of plant DNA segments into their own genomes ( $\mathrm{Li}$ et al. 1996, Long et al. 1998) as well as vice versa (Wink 2008) have arisen. This could have led to certain endophytes having the ability to biosynthesize various 'phytochemicals' originating from their host plants (Tan \& Zou 2001, Strobel \& Daisy 2003, Idris et al. 2013). One typical example was the production of gibberellins from both fungi and plants (Zhao et al. 2011).

Disease symptoms might express miscommunication with the host rather than active pathogenicity, leading to the hypothesis that plants participate in or initiate the disease processes (Rodriguez \& Redman 2008, Aly et al. 2011). On the other hand, B. dothidea grows 'endophytically' in pedicels and spreads into the fruit a few weeks before they reach harvest maturity forming quiescent infections. On ripening, the fungus resumes growth and further invades the fruit (Plan et al. 2002).

The secondary metabolites of many organisms are employed by the modern medicine into the creation of pharmaceutical products, including, but not limited to: penicillin which is derived from the fungal secondary metabolites of Penicillium notatum, bacitracin which is derived from the secondary metabolites of the hard working prokaryote Bacillus subtilis and the platinum awarded taxol which is synthesized by various endophytes in Taxus spp (Abdou 2013). As of 2005, approximately 22,000 bioactive secondary metabolites from microorganisms have been described; about $8,600(38 \%)$ of these are of fungal origin, highlighting the biochemical richness of this diverse clade of eukaryotes (Xing \& Guo 2011, Higginbotham et al. 2013). They produce a number of important secondary metabolites: growth hormones, anticancer, anti-Alzheimer, anti-fungal, antibacterial, anti-diabetic and immunosuppressant compounds (Giménez et al. 2007, Idris et al. 2013, Wang et al. 2014). Natural products from endophytic fungi were observed to inhibit many pathogenic organisms including bacteria, fungi, viruses and protozoans (Petrini 1986, Horn et al. 1995, Strobel et al. 1999, Moreno et al. 2011).

Stating that Artemisia spp. is a genus of plant evaluated for medicinal and bio pesticide traits (Bailen et al. 2013, Nageeb et al. 2013, Joshi 2013), this study displays the bioactivity of the endophytes residing in seven plant species collected in China. In addition, the evolutionary relationships, the fungal diversity and the plant-species specificity were taken into observation.

\section{Materials \& Methods}

\section{Sampling and isolation techniques}

Samples of Artemisia spp.: A. tangutica, A. brachyloba, A. subulata, A. argy, A. scoparia and A. lavandulifolia were collected from Qichun and Wuhan South Lake (GPS coordinates at request) in October 2013. Three ecotypes of A. brachyloba were sampled: one from an ecologically cultivated field of aromatic plants (CH9) and the other two from wild areas (CH6 and $\mathrm{CH} 7)$ inside Qichun. A. lavandulifolia was collected from 3 types of microenvironments: waste (CH1), lake shore $(\mathrm{CH} 3)$ and agricultural land $(\mathrm{CH} 2)$ in Wuhan. Only one ecotype was sampled for the rest of the species. Specimens were preserved in a herbarium (College of Plant Science \& Technology, HAU, Wuhan; voucher numbers- codes in Table 1). From each plant species stems were cut, labelled and kept in paper bags at $4-5^{\circ} \mathrm{C}$ until transported to the laboratory and then processed within 24 hours.

Following Núñez-Trujillo et al. (2012), a surface sterilization method was used in order to suppress epiphytic microorganisms from the plant samples. The isolation procedure was performed according to Cosoveanu et al. (2014). In order to analyze the fungal diversity, each replicate of the distinct stem fragments was registered. When an endophyte was acquired in pure culture it was preserved (Czapek, $\mathrm{T}=5^{\circ}$ and Glycerol $20 \%$ DI H2O, $\mathrm{T}=-30^{\circ}$ ), bioactively tested and identified. 


\section{Genomic DNA extraction, amplification and identification}

The extraction procedure was carried out as described by Shu et al. (2014) with the following modifications: samples were centrifuged for $15 \mathrm{~min}$ at $12.000 \mathrm{rpm}$; after the chloroform procedure the supernatant was mixed with $10 \%$ Sodium acetate and $60 \%$ Isopropyl alcohol, incubated for 10 min at $-30^{\circ} \mathrm{C}$ and centrifuged (10 min, 12.000rpm). Finally the pellet was washed twice with $75 \%$ ethanol (before maintained at $-20^{\circ} \mathrm{C}$ ) and centrifuged $(10 \mathrm{~min}, 12.000 \mathrm{rpm})$. The solvent was removed by evaporation, leaving the sample in the laminar flow cabinet. The purified DNA was resuspended in $20 \mu \mathrm{l}$ TE buffer $(10 \mathrm{mM}$ Tris-HCl, $\mathrm{pH} 8.0,1 \mathrm{mM}$ EDTA). RNase A was added and the sample was incubated for 1 hour at room temperature (long term storage at $-20^{\circ} \mathrm{C}$ ). For plants, stem fragments were sterilized superficially and sliced with only the laminae of medulla being availed of as material for the DNA extraction. These were carried out using Extract-N-Amp TM Plant PCR Kit according to the manufacturer's indications (Sigma-Aldrich Co.).

The molecular identification of the fungal strains was performed using ITS1 (5'TCCGTAGGTGAACCTGCGG-3') and ITS4 (5'-TCCTCCGCTTATTGATATGC-3') primer pair to amplify the 5.8S rDNA and the two internal transcribed spacers ITS1 and ITS2 (White et al. 1990). PCRs were performed according to Shu et al. (2014). As for plants, the nuclear ribosomal sequence was amplified using ITS2F as the forward primer and ITS2R as the reverse primer (Yao et al. 2010). PCR protocol was as follows: $94^{\circ} \mathrm{C}$ for $3 \mathrm{~min} ; 30$ cycles of $94^{\circ} \mathrm{C}$ for $30 \mathrm{~s}, 58^{\circ} \mathrm{C}$ for 30 $\mathrm{s}$, and $72^{\circ} \mathrm{C}$ for $1 \mathrm{~min}$ and $45 \mathrm{sec}$; and a final extension at $72^{\circ} \mathrm{C}$ for $10 \mathrm{~min}$. PCR products were purified using GenElute ${ }^{\mathrm{TM}}$ PCR Clean-Up Kit (Sigma-Aldrich Co.) and sequenced by Sangon Biotech (Shanghai, China) and Sequencing Services SEGAI (La Laguna, Spain). All sequences were submitted to GenBank under accession numbers KU 360596-KU360638. The sequences were run through the BLASTN search page using Megablast program (National Center for Biotechnology Information) where the most identical hits and their accession numbers were obtained (Table 1).

\section{Phylogeny analysis}

Sequences were aligned with the multiple alignment program ClustalW (Thompson et al. 1994) as implemented in Mega 6.0 (Tamura et al. 2013) and indels corrected manually to minimize alignment gaps (Foronda et al. 2011). Designated outgroup was Glomus sp. (GenBank Accession no. FJ164242.1). After the exclusion of non-overlapping leading/trailing gaps the length of the alignment was of $645 \mathrm{bps}$. Because of the high number of indels, the fragments were recoded as a binary matrix by means of the simple indel coding algorithm (Simmons \& Ochoterena 2000), appending the fragments to the nucleotide data as additional characters [as implemented in FastGap 1.21 (Borchsenius 2009)]. This "indel matrix" was used in all Bayesian analyses. Formerly, Gblocks program was used to eliminate poorly aligned positions and divergent regions (Dereeper et al. 2008). Best-fit models were compared in jModel test according to Akaike Information Criterion (AIC) and Bayesian Information Criterion (BIC) (Posada 2008). Best fit model for this ITS dataset was K80+G+I. Bayesian Inference analysis was conducted with MrBayes (Huelsenbeck \& Ronquist 2001) and run for $1 \times 10^{7}$ generations with a sampling frequency of $10^{2}$ generations. Of the resulting trees, the first 25.000 were discarded as burn-in and the following 75,001 trees were used to estimate topology and tree parameters. The percentage number of times a node occurred within these 75,001 was interpreted as the posterior probability of the node (Ramírez-Bahena et al. 2012). Convergence of the runs was indicated by an average standard deviation of split frequencies between duplicate runs of less than 0.01 ; starting value was 0.11 , values less than 0.01 were attained within the first $2.78 \times 10^{5}$ generations and final values were $\sim 0.002$. The consensus tree was visualized and edited using Treegraph software (Stöver \& Müller 2010).

\section{Dual culture assays}

Dual culture technique was the screening method employed to find endophytic fungi that produce metabolites which inhibit $S$. sclerotiorum, $F$. oxysporum and A. alternata growth in vitro. 
PDA plates were incubated at $25^{\circ} \mathrm{C}$ in darkness for 7 days and observed daily; plates were left for a further week to check the stability of the interaction. The following criteria were used to read the results:

0- No apparent interaction

1- Mycelia grow until making contact with each other and in the area where the contact is produced; morphological changes occur / slight growth inhibition of both fungi with narrow demarcation line (1-2 $\mathrm{mm})$

2- Pathogen growth is detained at a certain distance from the endophyte (> $2 \mathrm{~mm}$ )

RDP- Rapid development and parasitism of the endophyte

RD- Rapid development of the endophyte

RDL- Rapid development of the endophyte and lysed mycelia of the pathogen

L- Opponent fungus presents lysed mycelia

P- Endophyte displays parasitism on pathogen

\section{Bioactivity assays of endophytic extracts}

Fungal isolates (endophytic and pathogenic strains) were maintained on PDA, $\mathrm{T}=25^{\circ}$ in darkness while bacteria, Pectobacterium carotovorum and Klebsiella oxytoca, were maintained on LBA, $\mathrm{T}=28^{\circ}$ and $\mathrm{T}=32^{\circ}$ (respectively) in darkness. Pathogens were selected due to their different interactions with the host and their high economic importance: Alternaria alternata- seed borne, Fusarium oxysporum- vascular attack, Sclerotinia sclerotiorum- soil borne, Pectobacterium carotovorum- Gram negative degrading pectin and Klebsiella oxytoca- Gram negative, opportunistic pathogen of mammals and insects. Fungal and plant extract procedures and screening of potential antibacterial compounds ( $4 \mathrm{mg} / \mathrm{disc}$ ) have been performed according to Cosoveanu et al. (2012, 2013). Antifungal activity was checked using biometric agar dilution for S. sclerotiorum assays and spectrophotometry microplate and cuvette readings for $F$. oxysporum and A. alternata. Concentrations used were $1 \mathrm{mg} / \mathrm{ml}, 0.5 \mathrm{mg} / \mathrm{ml}, 0.1 \mathrm{mg} / \mathrm{ml}, 0.05 \mathrm{mg} / \mathrm{ml}, 0.01 \mathrm{mg} / \mathrm{ml}$ and $0.005 \mathrm{mg} / \mathrm{ml}$. The absorbance was read at 570nm. Each sample was replicated 8 times. Absorbance corrections were performed (cultivation media and extracts concentrations).

Growth of the target organisms in screening [1mg/ml] was compared with the control using Mann Whitney test and Wilcoxon matched pairs test $(\mathrm{p}<0.05)$. The Log-dose Probit regression model was used to obtain $\mathrm{EC}_{50}$ where the dose-effect response was observed (Mondino et al. 2015). All analysis were made using IBM SPSS Statistics 21.0.

\section{Fungal diversity}

The colonization rate was calculated as the total number of stem fragments in a sample (plant) yielding at least one isolate divided by the total number of stem fragments in that sample. The isolation rate was expressed as the total number of isolates yielded by a given sample (plant) divided by the total number of stem fragments in that sample. Frequency (\%) was calculated as the total number of fragments in a sample (plant/location) colonized by a species divided by the total number of fragments plated. The Shannon diversity index was calculated according to the formula $\mathrm{H}=\sum_{\mathrm{i}=1}^{S} \mathrm{pi} \ln \mathrm{pi}$, where $\mathrm{s}$ is the total number of species and pi is the relative proportion of each species. The species evenness was estimated with Shannon's equitability index according to the formula: $\mathrm{EH}=\mathrm{H} / \mathrm{Hmax}$, where $\mathrm{H}$ max is the maximum value of $\mathrm{H}$, equal to $\ln \mathrm{S}$. Margalef's index of diversity was calculated using the formula $(\mathrm{S}-1) / \ln \mathrm{N}$, where $\mathrm{S}$ is the number of species and $\mathrm{N}$ is the total number of individuals in the sample. The dominance of Simpson was calculated according to the formula $\mathrm{D}=\Sigma \mathrm{ni}(\mathrm{ni}-1) / \mathrm{N}(\mathrm{N}-1)$, where ni is the number of individuals belonging to $\mathrm{i}$ species and $\mathrm{N}$ is the total number of individuals. The diversity of Simpson was calculated as $1-\mathrm{D}$ and the evenness of Simpson was calculated as D / S, where S is the total number of different species. Finally the dominance of Berger Parker was calculated as DBP $=$ Nmax / N, where Nmax is the number of the most abundant species and $\mathrm{N}$ is the total number of species. The reciprocal form of Berger Parker index was also applied, 1 / DBP. 
Table1 Endophytic fungi's host plants (species and codes); endophytic fungi's codes, species, GenBank accession numbers, most similar sequences accession numbers and identity between query and hits.

\begin{tabular}{|c|c|c|c|c|c|c|}
\hline Plant species & Plant code & EF codes & EF species & $\begin{array}{l}\text { EF } \\
\text { Accession No. } \\
\end{array}$ & $\begin{array}{l}\text { Hit } \\
\text { Accession No. }\end{array}$ & Identity \\
\hline \multirow{4}{*}{ A. argy } & \multirow{4}{*}{$\mathrm{CH} 10$} & $\mathrm{HCH} 280$ & Alternaria alternata & KU360605 & KJ526175.1 & $100 \%$ \\
\hline & & $\mathrm{HCH} 288$ & Nigrospora oryzae & KU360608 & KF516962.1 & $99 \%$ \\
\hline & & $\mathrm{HCH} 285$ & Nigrospora sphaerica & KU360607 & KC505176.1 & $99 \%$ \\
\hline & & $\mathrm{HCH} 284$ & Curvularia geniculata & KU360606 & HE861840.1 & $99 \%$ \\
\hline \multirow{10}{*}{ A. brachyloba } & \multirow{6}{*}{$\mathrm{CH} 6$} & HCH330 & Diaporthe longicolla & KU360629 & JQ753971.1 & $99 \%$ \\
\hline & & $\mathrm{HCH} 328$ & Colletotrichum capsici & KU360628 & JX867217.1 & $96 \%$ \\
\hline & & НCH326 & Nigrospora sphaerica & KU360627 & KC505176.1 & $99 \%$ \\
\hline & & HCH323 & Cercospora capsici & KU360625 & HQ700353.1 & $99 \%$ \\
\hline & & $\mathrm{HCH} 332$ & Rhizoctonia solani & KU360630 & KJ152163.1 & $100 \%$ \\
\hline & & HCH325 & Curvularia geniculata & KU360626 & HE861840.1 & $99 \%$ \\
\hline & $\mathrm{CH} 7$ & $\mathrm{HCH} 256$ & Alternaria alternata & KU360596 & JX406532.1 & $100 \%$ \\
\hline & \multirow{3}{*}{$\mathrm{CH} 9$} & HCH320 & Nigrospora oryzae & KU360622 & JQ863242.1 & $99 \%$ \\
\hline & & HCH322 & Nigrospora sphaerica & KU360624 & JN198501.1 & $98 \%$ \\
\hline & & НCH321 & Alternaria alternata & KU360623 & KJ526175.1 & $100 \%$ \\
\hline \multirow{15}{*}{ A. lavandulifolia } & \multirow{8}{*}{$\mathrm{CH} 1$} & $\mathrm{HCH} 260$ & Diaporthe ceratozamiae & KU360597 & JQ044420.1 & $99 \%$ \\
\hline & & $\mathrm{HCH} 266$ & Colletotrichum gloeosporioides & KU360599 & GU066673.1 & $99 \%$ \\
\hline & & $\mathrm{HCH} 271$ & Colletotrichum gloeosporioides & KU360602 & JN887346.1 & $99 \%$ \\
\hline & & HCH334 & Colletotrichum gloeosporioides & KU360631 & JN887346.1 & $99 \%$ \\
\hline & & $\mathrm{HCH} 267$ & Nigrospora sp. & KU360600 & JF817271.1 & $99 \%$ \\
\hline & & $\mathrm{HCH} 263$ & Botryosphaeria dothidea & KU360598 & JN809914.1 & $99 \%$ \\
\hline & & $\mathrm{HCH} 269$ & Botryosphaeria dothidea & KU360601 & KF293883.1 & $99 \%$ \\
\hline & & $\mathrm{HCH} 335$ & Botryosphaeria dothidea & KU360632 & KC197764.1 & $97 \%$ \\
\hline & \multirow{4}{*}{$\mathrm{CH} 2$} & HCH306 & Diaporthe hordei & KU360617 & KC343120.1 & $98 \%$ \\
\hline & & $\mathrm{HCH} 304$ & Penicillium chrysogenum & KU360615 & JN851002.1 & $99 \%$ \\
\hline & & НCH310 & Neofusicoccum parvum & KU360618 & KJ381071.1 & $99 \%$ \\
\hline & & HCH305 & Alternaria alternata & KU360616 & JX985742.1 & $99 \%$ \\
\hline & \multirow{3}{*}{$\mathrm{CH} 3$} & HCH317 & Nigrospora sphaerica & KU360620 & KJ767121.1 & $99 \%$ \\
\hline & & НCH311 & Botryosphaeria dothidea & KU360619 & KC197789.1 & $99 \%$ \\
\hline & & НCH314 & Aspergillus flavus & KU360621 & LN482585.1 & $99 \%$ \\
\hline \multirow{6}{*}{ A. scoparia } & \multirow{6}{*}{ CH11 } & HCH337 & Diaporthe sp. & KU360633 & DQ145734.1 & $99 \%$ \\
\hline & & НCH345 & Nigrospora oryzae & KU360637 & JQ863242.1 & $99 \%$ \\
\hline & & НCH343 & Nigrospora sphaerica & KU360636 & KC505176.1 & $99 \%$ \\
\hline & & НCH339 & Alternaria alternata & KU360634 & KJ526175.1 & $100 \%$ \\
\hline & & НCH341 & Alternaria alternata & KU360635 & JX406532.1 & $100 \%$ \\
\hline & & $\mathrm{HCH} 346$ & Alternaria alternata & KU360638 & KJ526175.1 & $99 \%$ \\
\hline \multirow{3}{*}{ A. subulata } & \multirow{3}{*}{$\mathrm{CH} 8$} & $\mathrm{HCH} 295$ & Alternaria alternata & KU360612 & KJ008698.1 & $99 \%$ \\
\hline & & $\mathrm{HCH} 297$ & Alternaria alternata & KU360613 & KF293964.1 & $99 \%$ \\
\hline & & $\mathrm{HCH} 300$ & Curvularia spicifera & KU360614 & KC315931.1 & $99 \%$ \\
\hline \multirow{2}{*}{ A. tangutica } & \multirow{2}{*}{$\mathrm{CH} 4$} & $\mathrm{HCH} 279$ & Alternaria alternata & KU360604 & KJ526175.1 & $99 \%$ \\
\hline & & $\mathrm{HCH} 274$ & Curvularia intermedia & KU360603 & HE861855.1 & $98 \%$ \\
\hline \multirow{3}{*}{ Artemisia sp. } & \multirow{3}{*}{$\mathrm{CH} 5$} & $\mathrm{HCH} 289$ & Nigrospora sphaerica & KU360609 & KJ767121.1 & $99 \%$ \\
\hline & & $\mathrm{HCH} 293$ & Nigrospora sphaerica & KU360610 & KJ767121.1 & $99 \%$ \\
\hline & & $\mathrm{HCH} 294$ & Aspergillus aculeatus & KU360611 & KJ653817.1 & $97 \%$ \\
\hline
\end{tabular}

The statistical significance between the ranks of the isolates from both localities was questioned using paired wise Wilcoxon Signed Ranks Test (IBM SPSS 21.0) as the data could not fill the assumption for normal distribution, nor could the samples be regarded as independent.

\section{Results \& Discussion}

Isolation and identification of endophytic fungi in Artemisia spp. (Table1)

Of all the fungi recovered from a single host plant only the morphologically different 
endophytes were selected for further preservation and analysis (97 isolates). The similar non purified isolated fungi were recorded and used for frequency and biodiversity indices. Morphological identification of the pure isolates was carried out based on macroscopic and microscopic observations using taxonomic keys (Arx 1981) so only the different isolates were subjected to DNA analysis. 21 species were identified as belonging to one of the following genera: Diaporthe, Colletotrichum, Nigrospora, Botryosphaeria, Aspergillus, Penicillium, Neofusicoccum, Cercospora, Rhizoctonia, Alternaria and Curvularia. Results from macroscopic and microscopic characteristics were congruent with results of ITS sequence blasting analysis of these isolates, less in the case of the species of Cochliobolus (HE861840.1, HE861840.1, KC315931.1 and HE861855.1) where only asexual forms of Curvularia were isolated. Furthermore, to obtain an even higher probability of matching, Bayesian tree was used to select the most similar sequence according to GenBank.

\section{Phylogenetic analysis}

The 5.8S rDNA and the ITS1 and ITS2 juxtaposed regions molecular phylogenetic reconstruction of Artemisia spp. fungal endophytes (Fig. 1) shows 2 distinct clades having a long edge length, distinguishing the Ascomycota taxa from the Basidiomycota taxon, Rhizoctonia solani. Inside the Ascomycota clade, Diaporthaceae forms a separate tree from the other families (Pleosporaceae, Botryosphaeriaceae, Trichocomaceae, Mycosphaerellaceae, Glomerellaceae and Trichosphaeriaceae). The tree of the remaining families is divided into two subtrees with Pleosporaceae, Botryosphaeriaceae, Mycosphaerellaceae (Dothideomycetes) and Trichocomaceae (Eurotiomycetes) on one side and Glomerellaceae and Trichosphaeriaceae (Sordariomycetes) on the other. One interesting aspect, given that Diaporthaceae is a member of Sordariomycetes, is the lack of a monophyletic clade (Hyde et al. 2011, Jaklitsch et al. 2016). Additionally, Neofusiccocum parvum though a member of Botryosphaeriaceae, shares only one common ancestor with each of Botryosphaeriaceae, Mycosphaerellaceae and Pleosporaceae families. This does not suggest that $N$. parvum is any close to Botryosphaeriaceae family than the other two families afore mentioned. Despite these 2 interferences the tree reflects the affiliation of genera to their families and classes. Multigene phylogenies strongly support the acceptance of the genera Alternaria and Curvularia (Jumpponen \& Trappe 1998, García et al. 2012, Ariyawansa et al. 2015). Here both genera cluster in a well-supported clade within the family Pleosporaceae (PPs $=1)$.

From another point of view inside Nigrospora genus, no correlation could be made related to plant-endophyte species specificity. Two nested species specific clades are formed: one clade for $N$. oryzae, excepting undefined Nigrospora sp. isolate $\mathrm{HCH} 267$, and a second one for $N$. sphaerica (though with low PPs of 0.86 and 0.73). The isolates inside each clade are dwelling in different plant species. The rest of the $N$. sphaerica isolates were not forming a species specific clade with the correspondent ones and neither were they isolated from the same host species as the ones which do form a species specific clade. Moreover, HCH293, HCH289 and HCH317 had the same branch length but only the first two isolates were obtained from the same plant species.

The latter observation is sustained by Botryospaheria dothidea clade in which isolate $\mathrm{HCH} 335$ is presented as a younger event in the evolution of the tribe than the other two isolates (HCH269 and $\mathrm{HCH} 263$ ) all isolated from the same plant, $\mathrm{CH} 1$. Furthermore, though the same host plant species, $\mathrm{CH} 1$ and $\mathrm{CH} 3$ have different locations; $\mathrm{HCH} 263$ and $\mathrm{HCH} 269$ belonging to $\mathrm{CH} 1$ are closer to $\mathrm{HCH} 311$ dwelling in $\mathrm{CH} 3$ than to $\mathrm{HCH} 335$ hosted by $\mathrm{CH} 1$. The relationship between the two species of Aspergillus found in this study is similar to that obtained by Perrone et al. (2007). Despite the species' variability with the same identity and similar query covers from GenBank, according to Bayesian tree, the same species of A. alternata was selected for all of the isolates clustered in the same clade (PPs $=1$ ). Note that for Curvularia isolates the most similar sequences found had been identified as Cochliobolus spp. Neither the articles cited inside sequences assignments nor do our microscopic observations ensure a sexual state of the isolates. All accession numbers of the selected hits, identities and host plants are shown in Table 1. 

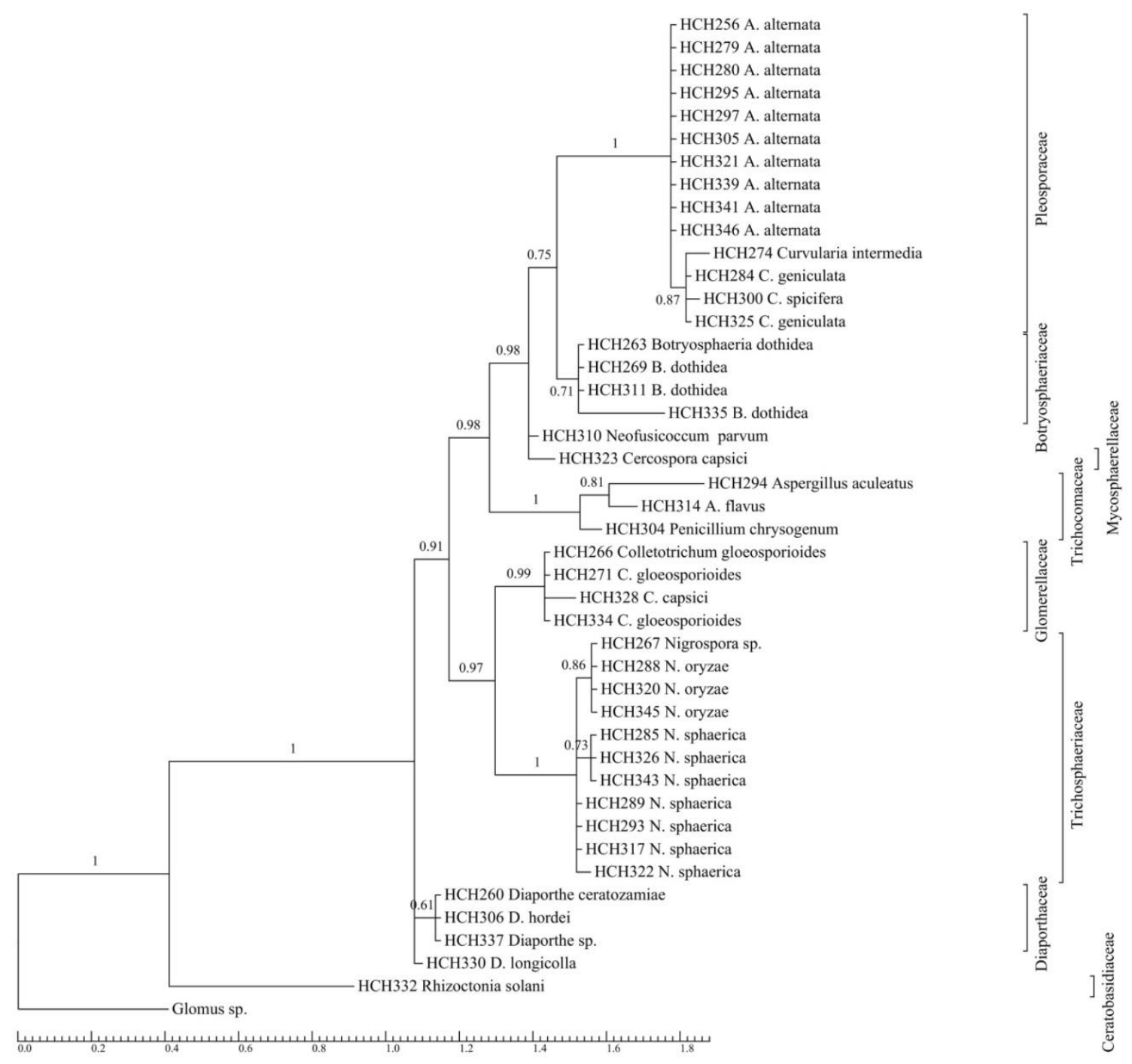

Fig. 1 - Phylogram of Bayesian inference phylogenetic analysis of ITS1-5.8S-ITS2 region sequences for endophytic fungi (EF) and the outgroup Glomus sp. The Bayesian clade-credibility values (posterior probabilities) are shown above the nodes. Host plants are presented in parentheses. Taxonomic families of the EF are shown in the right side of the tree.

\section{Fungal diversity}

\section{Colonization rate and Isolation rate}

With respect to colonization rate and isolation rate, no relations could be established between plant species and/or their localities (Table 2). Yet, it is to be mentioned that the lowest value in colonization rate was found in $\mathrm{CH} 9$ which was sampled from an ecologically cultivated area with medicinal plants in Qichun; the rest of the sampling being performed in a wild area.

\section{Colonization frequency per plant}

Only the highest incidences have been underlined: Nigrospora sphaerica in Artemisia sp. (CH5), Nigrospora oryzae in A. argy, Alternaria alternata in A. subulata and A. tangutica and B. dothidea in A. lavandulifolia (Table 2). Various reports upon Alternaria spp. and Botryospheria spp. in Artemisia spp. confirm the high incidence of these endophytes (Huang et al. 2007). On the other hand, to our knowledge, species of Nigrospora have not been reported to populate Artemisia species. During different studies of the authors, Chinese and Romanian ecotypes of Artemisia were observed as hosts but not Indian and Canarias ecotypes. 
Table 2 Endophytic fungi: colonization frequency per plant and per sampled site; colonization rate and isolation rate per plant.

\begin{tabular}{|c|c|c|c|c|c|c|c|c|c|c|c|c|c|c|}
\hline \multirow[b]{2}{*}{ EF species } & \multirow[b]{2}{*}{ CH1 } & \multirow[b]{2}{*}{$\mathrm{CH} 2$} & \multirow[b]{2}{*}{ CH3 } & \multirow[b]{2}{*}{ CH4 } & \multirow[b]{2}{*}{ CH5 } & \multirow[b]{2}{*}{ CH6 } & \multicolumn{2}{|c|}{ CF (\%) } & \multirow[b]{2}{*}{ CH8 } & \multirow[b]{2}{*}{ CH10 } & \multirow[b]{2}{*}{ CH11 } & \multirow[b]{2}{*}{ WU } & \multirow[b]{2}{*}{ QI } & \multirow[b]{2}{*}{ Total } \\
\hline & & & & & & & CH7 & СH9 & & & & & & \\
\hline A. alternata & & 41.60 & & 83.30 & & & 16.60 & 8.30 & 58.30 & 33.30 & 33.30 & 12.80 & 31.00 & 25.50 \\
\hline A. aculeatus & & & & & 8.30 & & & & & & & 0.00 & 1.07 & 0.70 \\
\hline A. flavus & & & 25.00 & & & & & & & & & 8.30 & 0.00 & 2.32 \\
\hline B. dothidea & 41.60 & & 41.60 & & & & & & & & & 27.70 & 0.00 & 7.75 \\
\hline C. capsici & & & & & & 25.00 & & & & & & 0.00 & 3.20 & 2.32 \\
\hline C. geniculatus & & & & & & 16.60 & & & & 8.30 & & 0.00 & 3.20 & 2.32 \\
\hline C. intermedius & & & & 16.60 & & & & & & & & 0.00 & 2.10 & 1.50 \\
\hline C. spicifer & & & & & & & & & 16.60 & & & 0.00 & 2.10 & 1.50 \\
\hline C. capsici & & & & & & 25.00 & & & & & & 0.00 & 3.20 & 2.32 \\
\hline C. gloeosporioides & 41.60 & & & & & & & & & & & 13.80 & 0.00 & 3.87 \\
\hline D. ceratozamiae & 8.30 & & & & & & & & & & & 2.70 & 0.00 & 0.70 \\
\hline D. hordei & & 8.30 & & & & & & & & & & 2.70 & 0.00 & 0.70 \\
\hline D. longicolla & & & & & & 16.60 & & & & & & 0.00 & 2.10 & 1.50 \\
\hline Diaporthe sp. & & & & & & & & & & & 8.30 & 0.00 & 1.07 & 0.70 \\
\hline N. parvum & & 8.30 & 2.70 & & & & & & & & & 2.70 & 0.00 & 0.70 \\
\hline N. oryzae & & & & & & & & 8.30 & & 50.00 & 16.60 & 0.00 & 3.20 & 2.32 \\
\hline Nigrospora sp. & 8.30 & & & & & & & & & & & 2.70 & 0.00 & 0.70 \\
\hline N. sphaerica & & & 8.30 & & 100.00 & 16.60 & & 8.30 & & 25.00 & 25.00 & 2.70 & 20.43 & 15.5 \\
\hline P. chrysogenum & & 8.30 & & & & & & & & & & 2.70 & 0.00 & 0.70 \\
\hline R. solani & & & & & & 16.60 & & & & & & 0.00 & 2.10 & 1.50 \\
\hline CR & 1.00 & 0.80 & 0.90 & 0.90 & 1.00 & 1.00 & 0.70 & 0.40 & 0.90 & 0.90 & 0.90 & & & \\
\hline IR & 1.75 & 0.92 & 0.92 & 1.00 & 1.08 & 1.33 & 0.67 & 0.42 & 1.75 & 1.33 & 1.50 & & & \\
\hline
\end{tabular}

EF- endophytic fungi; CF- colonization frequency; CR- colonization rate; IR- isolation rate; WU- Wuhan; QI- Qichun

Lowest values of $D$. ceratozamiae and $D$. hordei inside A. lavandulifolia and their absence from the other species, in terms of species specificity, differ from the values presented in a previous study in which Diaporthe was found in all of the three Chinese Artemisia species (Huang et al. 2007). To the best of our knowledge P. chrysogenum and N. parvum were isolated for the first time from Artemisia spp. Colletotrichum gloeosporoides had a specific incidence in A. lavandulifolia (41.6\%) as its relative C. capsici in A. brachyloba (25\%). A lavandulifolia and A. brachyloba were the only two plants with the highest variety in endophytic species (10 and 9 species, respectively). $B$. dothidea (41.6\%) and C. gloeosporoides (41.6\%) were the dominant endophytes in $A$. lavandulifolia. A. tangutica, A. subulata, and A. scoparia are dominated by A. alternata (83.3\%, 58.3\% and 33.3\%, respectively). A. argy and Artemisia sp. (CH5) resulted in a high incidence of $N$. oryzae and $N$. sphaerica, respectively.

As for plant species specificity, only $N$. spaherica, $N$. oryzae and A. alternata were present in various plants; except for $C$. geniculatus isolated from A. brachyloba and A. argy. Specificity of some fungus/plant interactions has been widely assumed at least at the genetic level, and it has been claimed that endophyte communities (or at least community profiles) are usually specific at the host species level (Fisher et al. 1992). Studies in the tropics (Arnold \& Lutzoni 2007) have identified distinct host-related communities in tropical tree leaves, but on a quantitative rather than qualitative basis. Thus, few endophytic fungi were found to be entirely restricted to particular plant species, but significant differences were found in the frequency of infection of individual morphotaxa. This phenomenon has been termed as host preference, following similar observations of decomposer fungal communities by Lodge (1997). As expected, the Alternaria genus was the dominant one, being by far one of the most cosmopolite endophytes reported. Surprisingly Nigrospora received displayed the second highest rate of occurrence in our analysis, followed by Botryosphaeria whose incidence has been described more in woody plants.

\section{Colonization frequency distribution by localities}

Only two species were isolated from both locations: A. alternata and N. sphaerica (Table 2). This indicates a true distinction in the diversity of fungal species found in Qichun and Wuhan. Moreover the same degree of occurrence is maintained as in the colonization frequency per plant species. The distribution showed statistical significance $(\mathrm{p}=0.027)$. 


\section{Fungal diversity indices}

The isolated biodiversity is likely to be much lower than the real one as the isolated endophytic communities will be biased towards faster growing fungi that are capable of rapid development on sugar high media like Colletotrichum, Phomopsis, Phyllosticta, and Xylaria species (Hyde \& Soytong 2008). Two of the selected indices (Margalef and Shannon) are mainly influenced by range, two (Simpson and Berger-Parker) are defined as dominance measures while two (Shannon Evenness and Simpson's evenness) are considered measures of evenness (Lexerod \& Eid 2006).

The Shannon diversity index $(\mathrm{H})$ for Qichun is 1.56 and for Wuhan 1.0 (Table 3). Shannon's evenness states a higher equitability in Qichun, differing from the one resulted from Simpson's index of evenness. Simpson's index has been less used as it emphasizes disproportionately the most common species in the sample, making them insensitive to changes of diversity that affect only the non-dominant species (Jost 2006).

Margalef's index results show a higher species richness in Wuhan than Qichun (3.11 vs. 2.51) and Berger-Parker index results show a positive correlation of a higher dominance in Qichun (0.35) than in Wuhan (0.28). Consequently the reciprocal of Berger-Parker concluded a higher diversity in Wuhan (3.57) than in Qichun (2.86). On the other hand, Simpson's and Shannon's indices of diversity are giving contradictory results. Opposite results generated by Shannon's species richness and Simpson's diversity were debated through various studies (Peet 1974, Abou-Moustafa et al. 2013). Further, Simpson's dominance is higher in Qichun (0.19) than in Wuhan (0.15), Simpson's diversity is congruent with the dominance, Qichun-0.85 and Wuhan- 0.85 and finally the evenness is higher in Wuhan than in Qichun (0.08 vs. 0.076). As a counter argument comes Shannon's richness index with a higher value for Qichun (1.56) than Wuhan (1.00), maintaining the uniformity of distribution higher in Qichun (0.61) than in Wuhan (0.43). The species richness number which is higher in Qichun (12 vs. 10) is underlined by the presence of 6 different host plant species including 8 different plant populations versus 1 species and 3 different populations in Wuhan, respectively. More specifically, if one starts from the hypothesis of having a linear higher endophytic diversity in a higher number of plant samples altogether with a higher number of plant species then the present results showed that the outcome is not the predictable one. Having these preliminary data and results we may conclude intuitively that Wuhan's biodiversity is actually higher than Qichun's though Shannon's index values say the exact opposite. This may raise issues about not just the variation of diversity of species specificity of fungal endophytes but also about the distinct micro environments that promote different endophytic populations. The three Wuhan's ecotypes of $A$. lavandulifolia were collected from three types of microenvironments: waste, lake shore and agricultural land. The three ecotypes of A. brachyloba are distinct in that the CH9 samples were obtained from an ecologically cultivated field of aromatic plants while the rest were obtained from a wild area in Qichun. Of the 21 fungal species samples, only two (N. sphaerica and A. alternata) were found at both sites. Of the seven Artemsia species sampled, two species had three ecotypes. N. sphaerica was isolated only from $\mathrm{CH} 3(\mathrm{CH} 1, \mathrm{CH} 2$ and $\mathrm{CH} 3$ are the same species). A. alternata was isolated only once from both $\mathrm{CH} 2$ and $\mathrm{CH} 7$ (CH6, $\mathrm{CH} 7$ and $\mathrm{CH} 9$ being the same species). Also, these two fungal species have been isolated from other Artemisia species in Qichun. This may lead to a lack of endophyte-plant species specificity and rather a host preference issue. Besides, four different species of endophytic fungi revealed the highest values in bioactivity assays. $C$ geniculatus $(\mathrm{HCH} 325)$ and A. alternata $(\mathrm{HCH} 321)$ were isolated from the same plant species, but different ecotypes: A. brachyloba in Wuhan. On the other hand C. spicifer (HCH300) and B. dothidea ( $\mathrm{HCH} 311)$ were isolated from A. subulata and A. lavandulifolia, respectively, in Qichun. These results can neither establish a connection between plant species known activity and fungal isolates, nor provide proof with regard to which plant gathers more active fungi (apart from the fungal species belonging to A. brachyloba, however, this remains inconclusive as it was the only case). Finally, Berger-Parker Dominance is congruent with $\mathrm{D}_{\text {Simpson }}$ index stating that Qichun has a higher number of dominant species. The inversed formula of Berger-Parker shows that Wuhan has a higher diversity agreeing with Simpson's Diversity value. 
Table 3 Fungal endophytes: diversity indices for both sampled localities.

\begin{tabular}{lll}
\hline Diversity indices & WUHAN & QICHUN \\
\hline Margalef Species Richness & 3.11 & 2.51 \\
Berger Parker Dominance (D) & 0.28 & 0.35 \\
Berger Parker Dominance (1/D) & 3.57 & 2.86 \\
Shannon Wiener Species Richness & 1.00 & 1.56 \\
Shannon's Evenness (EH) & 0.43 & 0.61 \\
Simpson's Diversity & 0.85 & 0.81 \\
Simpson's Evenness & 0.08 & 0.07 \\
Simpson Dominance & 0.15 & 0.19 \\
\hline
\end{tabular}

Table 4 Endophytic fungi (EF): dual culture activity against phytopathogenic fungi.

\begin{tabular}{|c|c|c|c|c|}
\hline \multirow[b]{2}{*}{$\begin{array}{l}\text { EF } \\
\text { CODE }\end{array}$} & \multirow[b]{2}{*}{ EF IDENTITY } & \multicolumn{3}{|c|}{ Evaluation of the dual culture } \\
\hline & & S.sclerotiorum & A.alternata & F.oxysporum \\
\hline $\mathrm{HCH} 263$ & Botryosphaeria dothidea & 1 & 0 & 0 \\
\hline $\mathrm{HCH} 273$ & Alternaria alternata & 1 & 1 & 0 \\
\hline $\mathrm{HCH} 274$ & Curvularia intermedia & 0 & 0 & 1 \\
\hline $\mathrm{HCH} 284$ & Curvularia geniculata & $\mathrm{L}$ & 0 & 1 \\
\hline $\mathrm{HCH} 285$ & Nigrospora sphaerica & 2 & 0 & 0 \\
\hline $\mathrm{HCH} 288$ & Nigrospora oryzae & 0 & 0 & 1 \\
\hline $\mathrm{HCH} 289$ & Nigrospora sphaerica & 0 & $\mathrm{P}$ & $\mathrm{P}$ \\
\hline $\mathrm{HCH} 293$ & Nigrospora sphaerica & $\mathrm{L}$ & 2 & 0 \\
\hline $\mathrm{HCH} 294$ & Aspergillus aculeatus & $\mathrm{RDP}$ & $\mathrm{RD}$ & RDL \\
\hline НCH300 & Curvularia spicifera & 2 & 1 & 0 \\
\hline НCH304 & Penicillium chrysogenum & $\mathrm{RDP} ; 2$ & $2 ; \mathrm{L}$ & 0 \\
\hline НCH310 & Neofusicoccum parvum & 1 & 0 & 0 \\
\hline HCH314 & Aspergillus flavus & 0 & RDP & RDP \\
\hline HCH317 & Nigrospora sphaerica & 0 & 2 & $\mathrm{P}$ \\
\hline HCH321 & Alternaria alternata & 2 & 0 & 0 \\
\hline HCH322 & Nigrospora sphaerica & 0 & 0 & 1 \\
\hline HCH325 & Curvularia geniculata & 2 & 0 & 0 \\
\hline HCH326 & Nigrospora sphaerica & 0 & 0 & 1 \\
\hline $\mathrm{HCH} 328$ & Colletotrichum capsici & 2 & 0 & 0 \\
\hline $\mathrm{HCH} 330$ & Diaporthe longicolla & 0 & 1 & $\mathrm{P}$ \\
\hline НCH332 & Rhizoctonia solani & 0 & $\mathrm{P}$ & $\mathrm{P}$ \\
\hline HCH335 & Botryosphaeria dothidea & 0 & 1 & 0 \\
\hline $\mathrm{HCH} 343$ & Nigrospora sphaerica & 1 & 0 & $0 ; \mathrm{L}$ \\
\hline
\end{tabular}

EF- endophyte; S.s.- Sclerotinia sclerotiorum, A.a.- Alternaria alternata, F.o.- Fusarium oxysporum; RDP- Rapid development and parasitism of the endophyte; RD- Rapid development of the endophyte; RDL- Rapid development of the endophyte and lysed mycelia of the pathogen; L-Opponent fungus presents lysed mycelia; P- Parazitism of the endophyte on the pathogen; 0- No apparent interaction; 1- Mycelia grow until touching each other and in the area where the contact is produced morphological changes occur / Slight growth inhibition of both fungi with narrow demarcation line (1-2 mm); 2- Pathogen growth is detained at a certain distance from the endophyte (> $2 \mathrm{~mm})$

\section{In vitro bioactivity assays}

\section{Dual-culture assays}

All isolates irrespective of their identity were assayed in dual culture; only active fungi results against at least one pathogen are shown. S. sclerotiorum (S.s.) was the most defeated pathogen as 6 isolates (Nigrospora sphaerica, Curvularia spicifera, Penicillium chrysogenum, Alternaria alternata, Curvularia geniculata, Colletotrichum capsici) presented the highest bioactivity ( $>2 \mathrm{~mm})$ as antagonists; of which $P$. chrysogenum showed the highest activity against $A$. alternata (A.a.) also (Table 4). Also, two different isolates of $N$. sphaerica inhibited A. alternata at highest scores. 
Table 5 Bioactivity screening of plants and endophytic fungi extracts against phytopathogenic fungi: $\mathrm{PI} \%[1 \mathrm{mg} / \mathrm{ml}]$ and $\mathrm{EC}_{50}[\mathrm{mg} / \mathrm{ml}]$ (confidence limits).

\begin{tabular}{|c|c|c|c|c|c|}
\hline $\mathbf{E F}$ & Host plant & $\begin{array}{ll}\text { PI\% } & \text { EC }_{50}\end{array}$ & A. alternata & $\begin{array}{l}\text { oxysporum } \\
\text { ox }\end{array}$ & S. sclerotiorum \\
\hline $\begin{array}{l}\text { A. alternata } \\
\text { (HCH321) }\end{array}$ & $\begin{array}{l}\text { A. brachyloba } \\
\text { CH9 }\end{array}$ & PI\% & $29.81^{\mathrm{a}}$ & $33.2^{\mathrm{a}}$ & $42.4^{\mathrm{a}}$ \\
\hline $\begin{array}{l}\text { C. spicifer } \\
\text { (HCH300) }\end{array}$ & $\begin{array}{l}\text { A. subulata } \\
\text { CH8 }\end{array}$ & $\begin{array}{l}\mathrm{EC}_{50} \\
\mathrm{PI} \%\end{array}$ & 8.95 & $52.09^{\mathrm{a}}$ & $\begin{array}{l}>1 \\
77.9\end{array}$ \\
\hline HCH316 & A. lavandulifolia & $\begin{array}{l}\mathrm{EC}_{50} \\
\mathrm{PI} \%\end{array}$ & 4.36 & $19.4^{\mathrm{a}}$ & $\begin{array}{l}0.66(0.34-4.67) \\
5.93^{\mathrm{a}}\end{array}$ \\
\hline $\begin{array}{l}\text { B. dothidea } \\
\text { HCH311 }\end{array}$ & $\begin{array}{l}\text { A. lavandulifolia } \\
\mathrm{CH} 3\end{array}$ & $\mathrm{PI} \%$ & 85.79 & & 22.04 \\
\hline $\begin{array}{l}\text { C. } \\
\text { geniculatus } \\
\text { (HCH325) }\end{array}$ & $\begin{array}{l}\text { A. lavandulifolia } \\
\text { CH6 }\end{array}$ & $\begin{array}{l}\mathrm{EC}_{50} \\
\mathrm{PI} \%\end{array}$ & $\begin{array}{l}0.38(0.26-0.54) \\
91.09^{\mathrm{a}}\end{array}$ & $31.5^{\mathrm{a}}$ & $\begin{array}{l}>1 \\
100^{a}\end{array}$ \\
\hline $\begin{array}{l}\text { A. alternata } \\
(\mathrm{HCH} 273)\end{array}$ & $\begin{array}{l}\text { A. tangutica } \\
\text { CH4 }\end{array}$ & $\mathrm{EC}_{50}$ & $\begin{array}{l}0.03(0.01-0.06) \\
48.38^{\mathrm{a}}\end{array}$ & 2.53 & 6.56 \\
\hline HCH264 & $\begin{array}{l}\text { A. lavandulifolia } \\
\text { CH1 }\end{array}$ & & $47.64^{\mathrm{a}}$ & 4.1 & 0 \\
\hline $\begin{array}{l}\text { N. sphaerica } \\
\text { (HCH285) }\end{array}$ & $\begin{array}{l}\text { A. argy } \\
\text { CH10 }\end{array}$ & & $48.37^{\mathrm{a}}$ & $11.94^{\mathrm{a}}$ & 24.92 \\
\hline \multirow[t]{12}{*}{$\begin{array}{l}\text { D. hordei } \\
\text { (HCH306) }\end{array}$} & $\begin{array}{l}\text { A. lavandulifolia } \\
\mathrm{CH} 2\end{array}$ & & & 2.33 & \\
\hline & $\begin{array}{l}\text { A. lavandulifolia } \\
\text { CH1 }\end{array}$ & & $42.44^{\mathrm{a}}$ & $0^{\mathrm{a}}$ & 5.22 \\
\hline & $\begin{array}{l}\text { A. lavandulifolia } \\
\mathrm{CH} 2\end{array}$ & PI\% & 0 & $11.62^{\mathrm{a}}$ & 8.17 \\
\hline & $\begin{array}{l}\text { A. lavandulifolia } \\
\mathrm{CH} 3\end{array}$ & & $53.22^{\mathrm{a}}$ & $10.98^{a}$ & 6.43 \\
\hline & $\begin{array}{l}\text { A. tangutica } \\
\mathrm{CH} 4\end{array}$ & & 1 & $0^{\mathrm{a}}$ & 6.9 \\
\hline & $\begin{array}{l}\text { Artemisia sp. } \\
\text { CH5 }\end{array}$ & & $49.47^{\mathrm{a}}$ & $8.68^{\mathrm{a}}$ & 0 \\
\hline & $\begin{array}{l}\text { A. brachyloba } \\
\text { CH6 }\end{array}$ & & $48.53^{\mathrm{a}}$ & $11.59^{\mathrm{a}}$ & 5.16 \\
\hline & $\begin{array}{l}\text { A. brachyloba } \\
\text { CH7 }\end{array}$ & & $54.51^{\mathrm{a}}$ & $12.90^{\mathrm{a}}$ & $16.40^{\mathrm{a}}$ \\
\hline & $\begin{array}{l}\text { A. subulata } \\
\text { CH8 }\end{array}$ & & $37.91^{\mathrm{a}}$ & $18.88^{\mathrm{a}}$ & 0 \\
\hline & $\begin{array}{l}\text { A. brachyloba } \\
\text { CH9 }\end{array}$ & & 7.55 & $26.85^{\mathrm{a}}$ & 14.65 \\
\hline & $\begin{array}{l}\text { A. argy } \\
\text { CH10 }\end{array}$ & & $50.13^{\mathrm{a}}$ & $10.82^{\mathrm{a}}$ & 0 \\
\hline & $\begin{array}{l}\text { A. scoparia } \\
\text { CH11 }\end{array}$ & & $88.05^{\mathrm{a}}$ & $51.78^{\mathrm{a}}$ & 0 \\
\hline
\end{tabular}

a Mann Whitney test (2-tailed): statistically significant differences between control and PI\% ( $\mathrm{p}$ values $<0.05$ )

$[1 \mathrm{mg} / \mathrm{ml}]-\mathrm{mg}$ of extract $/ \mathrm{ml}$ of medium

The above mentioned isolates exhibited apparent parasitism (P) together with Diaporthe longicolla and Rhizoctonia solani, the latter being reported as parasitizing fungi in soil (Buttler 1957). N. sphaerica and $R$. solani also maintained the inhibition response against $F$. oxysporum and A. alternata. Rhizoctonia binucleata has been reported in antagonism interaction evidenced by 
competition of nutrients or infection sites, antibiosis and hyperparasitism (González García et al. 2006). No correlation between similar Nigrospora species and values could be made and neither between same plants species as hosts for endophytic species of Nigrospora and their antagonistic values. Yet, the most important antagonistic interaction was shown by 3 different strains of $N$. sphaerica (different host plants) against A. alternata and S. sclerotiorum. In this study $P$. chrysogenum acted as a powerful antagonist against A. alternata and $S$. sclerotiorum. The two isolates of $C$. spicifer and $C$. geniculatus, respectively maintained their previous activity from dual culture assay in the extracted secondary metabolites 'in vitro' assays with the lowest $\mathrm{EC}_{50}$ of 0.03 $\mathrm{mg} / \mathrm{ml}$ registered by $C$. geniculatus against A. alternata. Three interactions with pathogen's mycelia lysis (L) (explained by Gindrat 1979), were observed with C. geniculatus, Nigrospora sp. and $N$. sphaerica as antagonists. Manifestation of rapid development and apparent parasitism (RDP) were observed in the interactions of: Aspergillus aculeatus on S. sclerotiorum and Aspergillus flavus on F. oxysporum and A. alternata.

\section{Antifungal and antibacterial activity of endophytic extracts}

All host plants and eight different fungal extracts have been assayed against bacterial and fungal pathogens in a screening (Table 5). No effect was recognized on bacteria (data not shown) though antibacterial activity was reported before with several of the assayed endophytic species in this study (Rekha \& Shivanna 2014). Furthermore, lower concentrations were used only for some of the fungal extracts: $\mathrm{HCH} 321, \mathrm{HCH} 325, \mathrm{HCH} 311$ and $\mathrm{HCH} 300$. There were two Curvularia species with high activity against two specific pathogens ( $S$. sclerotiorum and A. alternata) found in this study. One previous study shows various mycotoxins isolated from species of Cochliobolus amongst which were ophiobolins (terpinoids), which possess inhibitory effects against fungi (Manamgoda et al. 2011). Xiao et al. (2014) studied B. dothidea isolated from Melia azadirachta and found it to be active against some pathogens, unveiling inside the chemical profile chaetoglobosins, a family of cytochalasans with wide range of biological activities targeting cytoskeletal processes. This reinforces the activity of $B$. dothidea ( $\mathrm{HCH} 311)$ against $A$. alternata. From all the plant extracts, only A. scoparia has highly inhibited A. alternata (PI\%= 88.05 at $1 \mathrm{mg} / \mathrm{ml}$ ), although none of the six hosted isolates has shown any antagonistic quality in dual culture assays.

\section{Conclusions}

Only two fungal species were found in both locations suggesting different diversities. This study offers arguments suggesting that fungal specificity is dependent on geographical area and microenvironment. As for colonization frequency per total, Nigrospora species are to be mentioned as their occurrence inside Artemisia has been considerably less referred to. Two genera and two new species were reported as endophytes in Artemisia spp. (Nigrospora, Curvularia, Neofusicoccum parvum and Penicillium chrysogenum). With respect to preliminary bioactivity, species of Nigrospora had various interactions as lysis and parasitism as well as presenting the highest values against all pathogens. Thus, isolates of this genus should be closely observed due to their variation in expression within an interaction with another fungus and last but not least because of their lack of occurrence inside Artemisia sp. Moreover, Curvularia with its two different species represents a target for the chemical profile as their $\mathrm{EC}_{50} \mathrm{~s}$ were the lowest found in all isolates. In order to optimize secondary metabolite production of endophytic fungi under laboratory conditions, a deeper understanding is needed of both: host-endophyte relationships at the molecular and genetic levels of biogenetic gene cluster regulation and the effects of the environmental changes and culture conditions on gene expression. Further research at advanced molecular level may offer better insights into endophyte biodiversity and the regulation of fungal secondary metabolism.

\section{Acknowledgements}

This work was supported by the Ministry of Education of China under Grant Chinese Government Scholarship (2013-2014 EU Window, number 2013CEU086) and by Foundation Caja 
Canarias under Grant Scholarships for Research (Call 2013).

We would like to thank Dr. Jose Ramon Arevalo Sierra (Department of Botany, Ecology and Plant Physiology; University of La Laguna) for his indications related to the biodiversity issues. We have a deep appreciation for Rhiannon Flavin (Cork Institute of Technology) who reviewed the English language of the manuscript.

\section{References}

Abdou R. 2013 - Bioactive metabolites from the endophyte Botryospheria obtusa of the medicinal plant Bidens pilosa. International Journal of Pharmacy and Pharmaceutical Sciences 5(3), 579-584.

Abou-Moustafa KT, Yasui Y, Guttman DS, Scott JA, Kozyrskyj AL. 2013 - Divergence as diversity measure. Application to gut microbiome analysis. Tech. Report for the Dept. of Computing Science, University of Alberta, No. TR13-05, 1-24.

Aly AH, Debbab A, Proksch P. 2011 - Fungal endophytes: Unique plant inhabitants with great promises. Applied Microbiology and Biotechnology 90(6), 1829-1845.

Arnold AE, Lutzoni F. 2007 - Diversity and host range of foliar fungal endophytes: Are tropical leaves biodiversity hotspots? Ecology 88(3), 541-549.

Ariyawansa HA, Thambugala KM, Manamgoda DS, Jayawardena R, Camporesi E, Boonmee S, Hyde KD. 2015 - Towards a natural classification and backbone tree for Pleosporaceae. Fungal Diversity 71(1), 85-139.

Arx JA von. 1981 - The genera of fungi sporulating in pure culture. 3dth ed. Germany: Strauss \& Cramer GmbH.

Bailen M, Julio LF, Diaz CE, Sanz J, Martinez-Diaz RA, Cabrera R, Burillo J, Gonzalez-Coloma A. 2013 - Chemical composition and biological effects of essential oils from Artemisia absinthium L. cultivated under different environmental conditions. Industrial Crops and Products 49, 102-107.

Borchsenius F. 2009 - FastGap 1.2.Department of Biosciences, Aarhus University. Denmark.

Buttler EE. 1957. Rhizoctonia solani as a parasite of fungi. Mycologia 49(3), 354-373.

Cosoveanu A, Da Silva E, Giménez C, Nuñez Trujillo G, Gonzalez Coloma A, Frias Viera I, Cabrera R. 2012 - Artemisia thuscula Cav . : Antibacterial, antifungal activity of the plant extracts and associated endophytes. Journal of Horticulture, Forestry and Biotechnology 16(1), 87-90.

Cosoveanu A, Cabrera R, Gimenez C, Iacomi BM, Gonzalez-Coloma A. 2013 - Antifungal activity of plant extracts against pre and post harvest pathogens. Scientific Papers Series A Agronomy LVI, 206-211.

Cosoveanu A, Gimenez-Marino C, Cabrera Y, Hernandez G, Cabrera R. 2014 - Endophytic fungi from grapevine cultivars in Canary Islands and their activity against phytopathogenic fungi. International Journal of Agriculture and Crop Sciences 7(15), 1497-1503.

Dereeper A, Guignon V, Blanc G, Audic S, Buffet S, Chevenet F, Dufayard JF, Guindon S, Lefort V, Lescot M, Claverie JM, Gascuel O. 2008 - Phylogeny.fr: Robust phylogenetic analysis for the non-specialist. Nucleic Acids Research 36 (Web Server issue), W465-9.

Fisher PJ, Petrini O, Petrini LE, Descals E. 1992 - A preliminary study of fungi inhabiting xylem and whole stems of olea europaea. Sydowia 44, 117-121.

Foronda P, López-González M, Hernández M, Haukisalmi V, Feliu C. 2011 - Distribution and genetic variation of Hymenolepidid cestodes in murid rodents on the Canary Islands (Spain). Parasites Vectors 4:185, 1-9.

García A, Rhoden SA, Filho CJR, Nakamura CV, Pamphile JA. 2012 - Diversity of foliar endophytic fungi from the medicinal plant Sapindus saponaria L. and their localization by scanning electron microscopy. Biological Research 45(2), 139-148.

Giménez C, Cabrera R, Reina M, González-Coloma A. 2007 - Fungal endophytes and their rol in plant protection. Current Organic Chemistry 11, 707-720. 
Gindrat D. 1979 - Biological soil disinfestation Chapter 12. In: Developments in agricultural and managed-forest ecology Soil disinfestation. Elsevier Scientific Publishing Company 6, 253287.

González García V, Portal Onco MA, Rubio Susan V. 2006 - Review. Biology and systematics of the form genus Rhizoctonia. Spanish Journal of Agricultural Research 4(1), 55-79.

Higginbotham SJ, Arnold AE, Ibañez A, Spadafora C, Coley PD, Kursar TA. 2013 - Bioactivity of fungal endophytes as a function of endophyte taxonomy and the taxonomy and distribution of their host plants. PLoS ONE 8(9), e73192 doi: 10.1371/journal.pone.0073192.

Horn WS, Simmonds MSJ, Schwartz RE, Blaney WM. 1995 - Phomopsichalasin, a novel antimicrobial agent from an endophytic Phomopsis sp. Tetrahedron 51(14), 3969-3978.

Huang W, Cai Y, Xing J, Corke H, Sun M. 2007 - A potential antioxidant resource: Endophytic fungi from medicinal plants. Economic Botany 61(1), 14-30.

Hu HL, Jeewon R, Zhou DQ, Zhou TX, Hyde KD. 2007 - Phylogenetic diversity of endophytic Pestalotiopsis species in Pinus armandii and Ribes spp.: evidence from rDNA and $\beta$-tubulin gene phylogenies. Fungal Diversity 24, 1-22.

Huelsenbeck JP, Ronquist F. 2001 - MRBAYES: Bayesian inference of phylogenetic trees. Bioinformatics 17(8), 754-755.

Hyde KD, Soytong K. 2008 - The fungal endophyte dilemma. Fungal Diversity. 33, 163-173.

Hyde KD, McKenzie EHC, KoKo TW. 2011 - Towards incorporating anamorphic fungi in a natural classification - checklist and notes for 2010. Mycosphere 2(1), 1-88.

Idris A, Al-tahir L, Idris E. 2013 - Antibacterial activity of endophytic fungi extracts from the medicinal plant Kigelia africana. Egyptian Academic Journal of Biological Sciences 5(1), 19.

Jaklitsch W, Baral HO, Lucking R, Thorsten Lumbsch H. 2016 - Syllabus of Plant Families Part1/2 Ascomycota. 13th Edition, Borntraeger Science Publishers.

Joshi RK. 2013 - Artemisia capillaris: Medicinal uses and Future Source for Commercial Uses from Western Himalaya of Uttrakhand. Asian Journal of Research in Pharmaceutical Sciences 3(3), 137-140.

Jost L. 2006 - Entropy and diversity. Oikos 113(2), 363-375.

Jumpponen A, Trappe JM. 1998 - Dark septate endophytes: A review of facultative biotrophic root-colonizing fungi. New Phytologist 140(2), 295-310.

Lexerod NL, Eid T. 2006 - An evaluation of different diameter diversity indices based on criteria related to forest management planning. Forest Ecology and Management 222, 17-28.

Li JY, Strobel GA, Sidhu R, Hess WM, Ford E. 1996 - Endophytic taxol producing fungi from Bald Cypress Taxodium distichum. Microbiology 142, 2223-2226.

Lodge DJ. 1997 - Factors related to diversity of decomposer fungi in tropical forests. Biodiversity and Conservation. 6(5), 681-688.

Long DM, Smidansky ED, Archer AJ, Strobel GA. 1998 - In vivo addition of telomeric repeats to foreign DNA generates extrachromosomal DNAs in the taxol-producing fungus Pestalotiopsis microspora. Fungal Genetics and Biology 24(3), 335-44.

Manamgoda DS, Cai L, Bahkali AH, Chukeatirote E, Hyde KD. 2011 - Cochliobolus: An overview and current status of species. Fungal Diversity 51, $3-42$.

Mondino P, Casanova L, Celio A, Bentacur O, Leoni C, Alaniz S. 2015 - Sensitivity of Venturia inaequalis to trifloxystrobin and difenocozanole in Uruguay. Journal of Phytopathology 163, $1-10$.

Moreno E, Varughese T, Spadafora C, Arnold AE, Coley PD, Kursar TA, Gerwick WH, CubillaRios L. 2011 - Chemical constituents of the new endophytic fungus Mycosphaerella sp. nov. and their anti-parasitic activity. Natural Products Communications 6(6), 835-840.

Nageeb A, Al-Tawashi A, Emwas AHM, Al-Talla ZAH, Al-Rifai N. 2013 - Comparison of Artemisia annua Bioactivities between Traditional Medicine and Chemical Extracts. Current Bioactive Compounds 9, 324-332. 
Núñez-Trujillo G, Cabrera R, Burgos-Reyes RL, Da Silva E, Giménez C, Cosoveanu A, Brito N. 2012 - Endophytic fungi from Vitis vinifera L. isolated in Canary islands and azores as potential biocontrol agents of Botrytis cinerea pers.:Fr. Journal of Horticulture, Forestry and Biotechnology 16(1), 1-6.

Pang KL, Vrijmoed LLP, Goh TK, Plaingam N, Jones EBG. 2008 - Fungal endophytes associated with Kandelia candel (Rhizophoraceae) in Mai Po Nature Reserve, Hong Kong. Botanica Marina 51, 171-178.

Peet RK. 1974 - The measurement of species diversity. Annual Review of Ecology and Systematics 5, 285307.

Perrone G, Susca A, Cozzi G, Ehrlich K, Varga J, Frisvad JC, Meijer M, Noonim P, Mahakamchanakul W, Samson RA. 2007 - Biodiversity of Aspergillus species in some important agricultural products. Studies in Mycology 59, 53-66.

Petrini O. 1986 - Taxonomy of endophytic fungi in aerial plant tissues. In: Fokkema NJ, van den Heuvel J. (eds). Microbiology of the phyllosphere. Cambridge, UK Cambridge University Press $175-187$.

Petrini O. 1996 - Ecological and physiological aspects of host specificity in endophytic fungi. In: Redlin SC, Carris LM (eds). Endophytic Fungi in Grasses and Woody Plants. APS Press, St Paul, MN 87-100.

Plan MRR, Joyce DC, Ogle HJ, Johnson GI. 2002 - Mango stem-end rot (Botryosphaeria dothidea) disease control by partial-pressure infiltration of fungicides. Australian Journal of Experimental Agriculture 42(5), 625-629.

Posada D. 2008 - jModelTest: Phylogenetic model averaging. Mol Biol Evol 25(7), 1253 - 1256.

Ramírez-Bahena MH, Hernández M, Peix T, Velázquez E, León-Barrios M. 2012 - Mesorhizobial strains nodulating Anagyris latifolia and Lotus berthelotii in Tamadaya ravine (Tenerife, Canary islands) are two symbiovars of the same species, Mesorhizobium tamadayense sp. nov. Systematic and Applied Microbiology 35(5), 334-341.

Rekha D, Shivanna MB. 2014 - Diversity, antimicrobial and antioxidant activities of fungal endophytes in Cynodon dactylon (L.) pers. and Dactyloctenium aegyptium (L.) P. beauv. International Journal of Current Microbiology and Applied Sciences 3(8), 573-591.

Rodriguez R, Redman R. 2008 - More than 400 million years of evolution and some plants still can't make it on their own: Plant stress tolerance via fungal symbiosis. Journal of Experimental Botany 59(5), $1109-1114$.

Schulz B, Boyle C. 2005 - The endophytic continuum. Mycological Research 109(6), 661-686.

Shu S, Zhao X, Wang W, Zhang G, Cosoveanu A, Ahn Y, Wang M. 2014 - Identification of a novel endophytic fungus from Huperzia serrata which produces huperzine A. World Journal of Microbiology and Biotechnology 30(12), 3101-3109.

Simmons MP, Ochoterena H. 2000 - Gaps as characters in sequence-based phylogenetic analyses. Systematic Biology 49(2), 369-381.

Slippers B, Wingfield MJ. 2007 - Botryosphaeriaceae as endophytes and latent pathogens of woody plants: diversity, ecology and impact. Fungal Biology Reviews 21, 90-106.

Stöver BC, Müller KF. 2010 - TreeGraph 2: Combining and visualizing evidence from different phylogenetic analyses. BMC Bioinformatics 11:7 doi 10.1186/1471-2105-11-7

Strobel GA, Miller RV, Martinez-Miller C, Condron MM, Teplow DB, Hess WM. 1999 Cryptocandin, a potent antimycotic from the endophytic fungus Cryptosporiopsis cf. quercina. Microbiology 145(8), 1919-1926.

Strobel G, Daisy B. 2003 - Bioprospecting for microbial endophytes and their natural products. Microbiology and Molecular Biology Reviews. 67(4), 491-502.

Suryanarayanan TS, Senthilarasu G, Muruganandam V. 2000 - Endophytic fungi from Cuscuta reflexa and its host plants. Fungal Diversity 4, 117-123.

Tamura K, Stecher G, Peterson D, Filipski A, Kumar S. 2013 - MEGA6: Molecular evolutionary genetics analysis version 6.0. Molecular Biology and Evolution 30(12), 2725-2729. 
Tan RX, Zou WX. 2001 - Endophytes: A rich source of functional metabolites. Natural Products Reports 18(4), 448-459.

Thompson JD, Higgins DG, Gibson TJ. 1994 - CLUSTAL W: Improving the sensitivity of progressive multiple sequence alignment through sequence weighting, position-specific gap penalties and weight matrix choice. Nucleic Acids Research 22(22), 4673-4680.

Toju H, Sato H, Yamamoto S, Kadowaki K, Tanabe AS, Yazawa S, Nishimura O, Agata K. 2013 How are plant and fungal communities linked to each other in belowground ecosystems? A massively parallel pyrosequencing analysis of the association specificity of root-associated fungi and their host plants. Ecology and Evolution 3(9), 3112-3124.

Wang W, Zhang G, Zhang X, Xia Q, Cosoveanu A, Ahn Y, Wang M, Shu S. 2014 - Construction of a T-DNA insertional library of Colletotrichum gloeosporioides ES026 strain and cloning of relevant gene of huperzine A biosynthesis pathway. Journal of Pure and Applied Microbiology 8(5), 3729-3738.

White TJ, Burns T, Lee S, Taylor J. 1990 - Amplification and sequencing of fungal ribosomal RNA genes for phylogenetics. In: Innis MA, Gelfand D H, Sninsky J J, White T J (eds). PCR protocols. A guide to methods and applications. San Diego, Calif: Academic Press, Inc. 315322.

Wink M. 2008 - Plant secondary metabolism: diversity, function and its evolution. Natural Products Communications 3, 1205-1216.

Xiao J, Zhang Q, Gao YQ, Tang JJ, Zhang AL, Gao JM. 2014 - Secondary metabolites from the endophytic Botryosphaeria dothidea of Melia azedarach and their antifungal, antibacterial, antioxidant, and cytotoxic activities. Journal of Agricultural and Food Chemistry 62(16), 3584-3590.

Xing X, Guo S. 2011 - Fungal endophyte communities in four Rhizophoraceae mangrove species on the south coast of China. Ecological Research 26(2), 403-409.

Yao H, Song J, Liu C, Luo K, Han J, Li Y, Pang X, Xu H, Zhu Y, Xiao P, Chen S. 2010 - Use of ITS2 region as the universal DNA barcode for plants and animals. PLoS ONE. 5(10):e13102.

Zhao J, Shan T, Mou Y, Zhou L. 2011 - Plant-derived bioactive compounds produced by endophytic fungi. Mini-Reviews in Medicinal Chemistry 11(2), 159-168. 